\title{
Cenários e desafios para formação de professores para educação profissional e tecnológica
}

\section{Scenarios and challenges for teacher training for professional and technological education}

\author{
1*, Flávia Monteiro de Barros Araujo ${ }^{1}$ Pablo Silva Machado Bispo dos Santos ${ }^{1}$, Priscila sabela \\ Priscila Araújo Guaiano Hage ${ }^{1}$
}

\begin{abstract}
RESUMO
A formação do professor é um tema recorrente, constituindo objeto de debate em diversos fóruns e uma preocupação para as autoridades educacionais. Embora com alguns avanços, o Brasil ainda não conseguiu solucionar as questões relativas à preparação do professor e de sua profissionalização. Este cenário se torna mais grave na educação profissional onde, tradicionalmente, docentes leigos atuaram e ainda atuam em instituições escolares. Em nosso estudo, com base na literatura e no exame dos documentos legais, buscamos resgatar a trajetória histórica deste processo marcado por avanços e dificuldades. Destaca-se a importância de se conhecer melhor a formação destes profissionais, tendo em vista a realiacao de investimentos para ampliação da oferta de cursos e, ainda, o fato de não encontramos um volume expressivo de trabalhos sobre a formação de professores para a educação profissional.
\end{abstract}

Palavras-chave: Formação de Professores; Educação profissional; História da Educaçao Profissional.

\begin{abstract}
Teacher training is a recurring theme, constituting an object of debate in several forums and a concern for educational authorities. Although with some advances, Brazil has not yet managed to resolve issues related to teacher preparation and professionalization. This scenario becomes more serious in professional education where, traditionally, lay teachers worked and still work in school institutions. In our study, based on the literature and on the examination of legal documents, we seek to rescue the historical trajectory of this process marked by advances and difficulties. The importance of knowing better the training of these professionals is highlighted, in view of the realization of investments to expand the offer of courses and, also, the fact that we did not find an expressive volume of works on the training of teachers for professional education.
\end{abstract}

Keywords: Teacher training; Professional education; History of Vocational Education.

\footnotetext{
${ }^{1}$ Universidade Federal Fluminense - UFF - *E-mail: flaviamonteiro@id.uff.br
} 


\section{INTRODUÇÃO}

A formação do professor é um tema recorrente na literatura, constituindo objeto de debate em diversos fóruns e ainda uma preocupação das autoridades educacionais. Embora com alguns avanços, o Brasil ainda não conseguiu solucionar as questões relativas à preparação do professor e de sua profissionalização. As necessidades de ampliação dos sistemas, fazem com que muitos docentes estejam em exercício sem a devida formação e consequente habilitação. Este cenário se torna mais grave na educação profissional onde, tradicionalmente, docentes leigos atuaram e ainda atuam em instituições escolares.

A educação profissional contempla processos formativos desenvolvidos em diferentes espaços educativos formais e não formais. Ao lado das instituições, públicas e privadas que integram o sistema de ensino, encontram-se, ainda, organizações não governamentais, patronais e sindicais, e mesmo comunitárias, que oferecem cursos com o objetivo de preparar os indivíduos para o mundo do trabalho.

Em nosso país, de acordo com a Lei de Diretrizes e Bases da Educação Nacional n ${ }^{\circ}$. 9394/96 (LDBEN), a educação profissional e tecnológica abrange cursos: de formação inicial e continuada ou qualificação; técnicos de nível médio e tecnológicos de graduação e pós-graduação. O curso básico destina-se à qualificação e profissionalização de trabalhadores, independente de escolaridade prévia; o técnico, objetiva habilitar alunos matriculados ou egressos do ensino médio, e o tecnológico, por sua vez, constitui uma formação em nível superior na área tecnológica.

Segundo a legislação, a educação profissional e tecnológica, em consonância com os objetivos da educação nacional, integra-se aos diferentes níveis e modalidades de educação e às dimensões do trabalho, da ciência e da tecnologia. Nas últimas décadas, a educação profissional passou por processo de expansão das matrículas e foi objeto de debates por diversos setores sociais que enfatizam a necessidade de formação de recursos humanos, tendo em vista as demandas do contexto de desenvolvimento econômico. Nesta direção, alguns pesquisadores expressam a preocupação com a escassez de pessoal qualificado para atender ao mercado de trabalho que cresce e se torna mais complexo. Este fato, desafia diversas instâncias a formularem políticas que deem conta da ampliação desta modalidade.

Historicamente as reflexões sobre esta modalidade estiveram relacionadas às discussões acerca da identidade e articulação com o ensino médio que, no cenário nacional, oscilou entre oferecer uma formação geral, propedêutica e ou estudos profissionalizantes. Esta organização da escola secundária, caracterizada pela literatura pedagógica como dual, tem raízes nos processos de divisão do trabalho na sociedade capitalista e relaciona-se à separação entre o trabalho manual e intelectual. 
Esta polêmica, envolvendo as finalidades do ensino médio, tornou-se mais acirrada nos períodos de elaboração das Leis de Diretrizes e Bases da Educação Nacional. Nesses momentos, registraram-se acirradas disputas entre forças políticas que defendiam projetos distintos de ensino médio. Isto ocorreu no contexto de formulação da Lei $n^{\circ}$. 4024/61, quando da Lei ${ }^{\circ}$. 5692/71 e, mais recentemente, quando da aprovação da Lei $n^{\circ}$. 9394/96. Estas normas que reorientaram a educação, imprimindo reformas em âmbito nacional, ora dissociaram a educação geral da profissional, ora buscaram articulá-las, tentando apontar caminhos para superação da dualidade da escola secundária. No calor deste debate, destaca-se o potencial da concepção de educação politécnica que objetiva à formação integral do ser humano e que coloca o trabalho como princípio educativo, indo além, entretanto, de uma formação submetida aos ditames do mercado de trabalho.

A concepção de educação politécnica tem raízes nas contribuições de Karl Marx e Gramsci e implica na relação entre escola e trabalho ou, ainda, entre formação intelectual e trabalho produtivo. Sobre a noção de politecnia, Saviani (1989) observa que esta diz respeito:

(...) ao domínio dos fundamentos científicos das diferentes técnicas que caracterizam o processo de trabalho moderno. Diz respeito aos fundamentos das diferentes modalidades de trabalho. Politecnia, nesse sentido, se baseia em determinados princípios, determinados fundamentos e a formação politécnica deve garantir o domínio desses princípios, desses fundamentos (p. 17).

O fato é que, após período de retração, a educação profissional vem novamente crescendo. De acordo com o Censo Escolar 2019:

O número de matrículas na educação profissional aumentou $0,6 \%$ em relação ao ano anterior, de acordo com os dados do Censo Escolar da Educação Básica 2019. Com o incremento de 11.519 alunos no total, o censo registrou 1.914 .749 matrículas no país. O Instituto Nacional de Estudos e Pesquisas Educacionais Anísio Teixeira (Inep), que realiza a pesquisa anualmente em parceria com as secretarias estaduais e municipais de educação, divulgou os resultados do Censo Escolar em 31 de janeiro.

Mas como organizar e desenvolver a educação profissional? Um dos grandes desafios na organização deste campo educativo é formar o docente que atua nas escolas de educação profissional. Em nosso estudo buscamos resgatar a trajetória histórica deste processo marcado por avanços e dificuldades, destacando marcos legais e questões decorrentes para a preparação dos professores para esta modalidade. Destaca-se a importância de se conhecer melhor as questões que envolvem a formação destes profissionais, tendo em vista a necessidade de investimentos para ampliação da oferta de cursos. E, ainda, apesar da relevância da educação profissional, não 
encontramos ainda um volume mais expressivo de trabalhos sobre a formação de professores para a educação profissional.

\title{
AS PRIMEIRAS INCIATIVAS
}

A formação de professores vem suscitando, há décadas, debates políticos e acadêmicos acalorados, tendo em vista a necessidade de preparar profissionais dotados das competências necessárias e em número suficiente para o desenvolvimento dos sistemas de ensino. Muito se discute sobre esse processo, suas fragilidades e potências, tendo em vista a definição de conhecimentos e práticas que devem ser construídos durante a formação inicial de professores. A literatura produziu diversos estudos sobre o tema, destacando a importância de processos que articulem no âmbito curricular teoria e prática para a formação de professores reflexivos inseridos num processo contínuo de desenvolvimento profissional.

Entretanto, na história recente da educação brasileira, contudo, ainda encontramos em exercício docentes sem preparação adequada, desconsiderando as exigências postas pela legislação para a formação profissional. Tal cenário é particularmente grave na educação profissional onde apesar dos diversos atos normativos, ainda oscila entre programas emergenciais e

\begin{abstract}
todo o caminho histórico da formação de professores para o ensino profissional de nível técnico moldou-a de forma a persistirem características como a condição de especial e de emergencial; um locus indefinido; a ausência de marcos regulatórios definidos; de saberes próprios
\end{abstract}

A formação de professores em cursos específicos é inaugurada no Brasil no Século XIX, com a implantação das escolas normais destinada aos docentes de Primeiras Letras. A primeira escola normal foi criada em 1835, em Niterói na Província do Rio de Janeiro, pela Lei $\mathrm{n}^{\circ} 10$, de 1835, e existe até hoje. A lei determinava o ensino do método mútuo ou lancasteriano para aqueles que se destinavam ao magistério primário. Este processo de implantação das escolas normais sofreu vários revezes, muitas escolas foram fechadas e enfrentaram dificuldades para seu funcionamento. Aos poucos, disseminava-se no país um modelo de preparação de docentes para os anos iniciais inspirado nos moldes das escolas normais francesas. (TANNURI, 2000)

Já no começo do século XX, detectamos a preocupação com a preparação de professores para o ensino secundário em cursos específicos. Nas primeiras décadas do século, o crescimento do setor industrial no país coloca em pauta a necessidade de maior escolarização por parte dos trabalhadores. Vale lembrar que temos a criação de 19 escolas de aprendizes e artífices no início do século XX, por meio do Decreto-Lei n 7.566 em 1909, pelo então presidente da república Nilo Peçanha. Segundo o texto do decreto: 
o augmento constante da população das cidades exige que se facilite ás classes proletarias os meios de vencer as difficuldades sempre crescentes da lucta pela existencia; que para isso se torna necessario, não só habilitar os filhos dos desfavorecidos da fortuna com o indispensavel preparo technico e intellectual, como fazel-os adquirir habitos de trabalho proficuo, que os afastará da ociosidade ignorante, escola do vicio e do crime;

A criação destas escolas marca o início de iniciativas formais em prol da educação profissional ainda, entretanto, imbuídas da concepção de que os trabalhos manuais eram dirigidos aos mais desfavorecidos pela fortuna e como medida de contenção social.

As Escolas de Aprendizes Artífices, contudo, não caminhavam bem. As instalações eram precárias e as oficinas mal aparelhadas, além de não contarem com professores e instrutores bem preparados para tarefa. De acordo com Fachada

(...) a falta de mestres de ofícios especializados e de professores qualificados era um entrave ao desenvolvimento desse tipo de ensino e foi um fator que influenciou diretamente o poder público a recrutar professores do ensino primário para atuar na rede, solução que não produziu resultados satisfatórios, tendo em vista que esses professores não possuíam habilitação necessária para atuar no ensino profissional. E quanto aos mestres de ofícios provenientes das fábricas e das oficinas, faltava-lhes o conhecimento suficiente para atender aos requisitos de base teórica, que eram demandados pelos cursos oferecidos.

A preocupação com a carência de professores para a educação profissional, motivou a realização de uma parceria entre o governo federal e a prefeitura do Rio de Janeiro, antigo Distrito Federal, para implantação da Escola Normal de Artes e Ofícios Wenceslau Brás, no Rio de Janeiro. A instituição foi criada pelo Decreto ${ }^{\circ}$. 1880, de 11 de agosto de 1917. De acordo com Fonseca, a Prefeitura do Distrito Federal cria a escola com a finalidade de preparar professores, mestres e contramestres para os estabelecimentos de ensino profissional, assim como professores de trabalhos manuais para escolas primárias. Esta escola constitui a primeira instituição específica voltada para preparação de docentes para educação profissional no Brasil, e habilitava professores, mestres e contramestres para as escolas profissionais. De acordo com Machado:

\begin{abstract}
A criação da Escola Normal de Artes e Ofícios Wenceslau Brás, em 1917, no antigo Distrito Federal, constitui o início dessas iniciativas, já impregnado pelas dificuldades que vieram a seguir. Fechada pouco tempo depois, em 1937, essa escola, embora tenha chegado a ter 5.301 matriculados durante este período, habilitou apenas 381 professores (309 mulheres), em sua grande maioria para atividades de trabalhos manuais em escolas primárias. Em menor número, professores, mestres e contramestres para escolas profissionais.
\end{abstract}

Nas primeiras décadas do século XX, inauguram-se diversas indústrias no país numa vigorosa expansão. Este movimento que tem origens no século anterior, no segundo império, coloca a necessidade de formação da mão de obra para o parque industrial e suscita preocupações acerca das escolas profissionais. A aceleração da industrialização está relacionada as dinâmicas da economia cafeeira e ao processo de urbanização. Segundo Fonseca (1962, pg. 49) 


\begin{abstract}
No início da primeira grande guerra, em 1914, o Brasil mandava vir do estrangeiro quase todos os produtos industriais de que precisava. Com as dificuldades de importação viram-se os brasileiros forçados a instalar, no país, grande número, iniciando-se, assim, a produção de muitos artigos de primeira necessidade. O país encetava um verdadeiro surto industrial. À falta de material estrangeiro, abria-se à indústria nacional o monopólio dos mercados internos; além disso, surgia a possibilidade da entrada de nossos produtos em outros países. E houve uma ânsia de produção. Por toda parte surgiam novas fábricas, novas indústrias. O movimento era, porém, mais acentuado nas grandes cidades, como Rio e São Paulo.
\end{abstract}

Esta preocupação motiva o deputado mineiro Fidélis Reis a apresentar, em 1922, um projeto de lei que criava o ensino profissionalizante obrigatório, em tempo integral. Aprovado após um longo período de tramitação, a lei não foi aplicada por falta de recursos orçamentários.

Na década de 1930, com o golpe de Vargas, o país passa por grandes transformações no plano social, econômico e político, destacando-se a preocupação do estado com a indução do desenvolvimento econômico e a implantação de uma infraestrutura. Neste contexto, a educação profissional recebe atenção da Constituição Federal de 1937 que estabeleceu a ditadura do estado novo. O texto legal, em seu art. 129, assinala a importância da implantação das escolas vocacionais e pré-vocacionais destinados as classes menos favorecidas, como primeiro dever do Estado e, ainda, menciona a colaboração das indústrias e sindicatos em criar, de acordo com suas especialidades, escolas de aprendizes destinadas aos filhos de operários e associados.

Com a criação do Sistema S a questão na década de 1940, amplia-se a oferta de cursos de formação de mão-de-obra para a indústria e o comércio. O SENAI é criado pelo Decreto-Lei 4.048 de 22 de janeiro de 1942, com o objetivo de preparar recursos humanos, e o Senac em 1946.

Com a aprovação das Leis Orgânicas da Educação Nacional, 1942-1946, conhecidas como reforma de Gustavo Capanema, há a incorporação de normas relativas à formação de professores para a educação profissional na Lei Orgânica do Ensino Industrial, que estabeleceu em seu art. $54, \S 1^{\circ}$ que a formação dos professores de disciplinas de cultura geral, de cultura técnica ou de cultura pedagógica, e de práticas educativas, deveria ser realizada em cursos apropriados. Além das questões relativas à formação de professores, essa lei traz uma importante inovação pois desloca todo ensino profissional para o grau médio, deixando a educação primária com um conteúdo geral. (CUNHA, 2005)

A aproximação do Brasil aos Estados Unidos durante a segunda guerra, gerou impactos para educação profissional e a formação de seus professores. Após tentar conseguir, sem sucesso, professores alemães, em 1936, e contratar docentes suíços para as escolas industriais, em 1941/42, o Ministério da Educação busca assistência técnica junto aos Estados Unidos com o objetivo de desenvolver a política industrialista de Vargas. Por sua vez, para os Estados Unidos o 
estabelecimento de uma parceria significava ampliar a sua influência no campo educativo no país num momento de acirramento e polarização da política internacional.

No momento posterior ao final da segunda guerra, em 1946, é criada a Comissão Brasileiro-Americana de Educação Industrial (CBAI), resultado de um programa de cooperação educacional para a formação de docentes para o ensino industrial, estabelecido entre o Brasil e dos Estados Unidos. Esta iniciativa partiu do Ministro Gustavo Capanema, mas só prosperou depois do fim do Estado Novo.

Segundo Fonseca, o programa da CBAI destacava doze pontos:

1) Desenvolvimento de um programa de treinamento e aperfeiçoamento de professores, instrutores e administradores; 2) Estudo e revisão do programa de ensino industrial; 3) Preparo e aquisição de material didático; 4) Ampliação dos serviços de bibliotecas; verificar a literatura técnica existente em espanhol e português; examinar a literatura técnica existente em inglês e providenciar sobre a aquisição e tradução das obras que interessarem ao nosso ensino industrial; 5) Determinar as necessidades do ensino industrial; 6) Aperfeiçoamento dos processos de organização e direção de oficinas; 7) Desenvolvimento de um programa de educação para prevenção de acidentes; 8) Aperfeiçoamento dos processos de administração e supervisão dos serviços centrais de administração escolar; 9) Aperfeiçoamento dos métodos de administração e supervisão das escolas; 10) Estudo dos critérios de registros de administradores e professores; 11) Seleção e orientação profissional e educacional dos alunos do ensino industrial; 159 12) Estudo das possibilidades do entrosamento das atividades de outros órgãos de educação industrial que não sejam administrados pelo Ministério da Educação, bem como a possibilidade de estabelecer outros programas de treinamento, tais como ensino para adultos, etc. (FONSECA, C.S., 1961, p. 565).

A CBAI foi responsável pela oferta do primeiro Curso de Aperfeiçoamento de Professores do Ensino Industrial, em 1947, no Rio de Janeiro, com duração de um ano e três meses. No âmbito deste convênio eram realizadas reuniões com diretores das escolas técnicas e industriais e cursos de aperfeiçoamento para docentes. Além da tradução de livros, foi produzido um boletim que veiculava notícias sobre esse segmento e ainda disseminado um método para aprendizagem dos ofícios industriais TWI (training within industry = treinamento em serviço).

Em 1957, foi instalado um Centro de Pesquisas e Treinamento de Professores para o ensino industrial que, mais tarde, foi incorporado a Escola Técnica e ao CEFET do Paranã (CUNHA, 2005).

Com a LDB $\mathrm{n}^{\mathrm{o}}$ 4.024/1961, artigo 59, dois caminhos separados foram estabelecidos para a formação de professores. Em faculdades de filosofia, ciências e letras, os que se destinassem ao magistério no ensino médio. Em cursos especiais de educação técnica, os que se habilitassem para disciplinas do ensino técnico. Este artigo, porém, demorou a ser regulamentado, o que aconteceu somente em 1967 e 1968. 
Segundo Machado (ibidem), a partir dos anos 60, o exercício do magistério na área da educação profissional passa a ser regulado pelo MEC mediante a sistemática de registro de professores. E há menção na legislação da educação brasileira de formação pedagógica para professores da EPT.

Com a aprovação da primeira Lei de Diretrizes e Bases em 1961, Lei n.4024/61, foi estabelecido que como instâncias formadoras de docentes o Curso Normal, os Institutos de Educação e as faculdades de Filosofia, Ciências e Letras, cada um atendendo a determinado segmento escolar.

Ainda em 1961, foi sancionada a Portaria Ministerial n 141 que estabeleceu orientações para o registro de professores dos cursos de Ensino Industrial: básico ou ginásio industrial, cursos de aprendizagem industrial e cursos industriais técnicos, com padrões diferenciados de exigência.

Em 1967, assistimos outra inciativa no campo da formação de professores da educação profissional, com a aprovação do o Parecer no 12/1967, que normatizou os Cursos Especiais de Educação Técnica, definindo que estes seriam organizados segundo estrutura própria compatível com cada ramo técnico - industrial, comercial e agrícola, mas com formação pedagógica similar. O Parecer CFE nº 12/1967 foi o primeiro dispositivo de regulamentação dos cursos especiais de educação técnica previstos pela LDB n ${ }^{\circ}$ 4.024/61 e teve basicamente o objetivo de esclarecer a finalidade destes cursos. Com base neste Parecer, a Portaria Ministerial n ${ }^{\circ}$ 111/68 esclareceu que tais cursos seriam destinados aos diplomados em nível superior ou em nível técnico em cujos currículos figurassem disciplinas escolhidas para lecionar e definiu o mínimo de 720 horas-aula. Cursos reservados a formar instrutores teriam, pelo menos, 200 horas-aula. O Art. 59 foi também regulamentado pelo Parecer CFE $n^{\circ} 479 / 68$, que estabeleceu a obrigatoriedade de seguir currículo mínimo e as orientações do Parecer n ${ }^{\circ}$ 262/62, que fixava a duração da formação dos professores do ensino médio geral, incluindo as posteriores disposições que viessem modificar, esclarecer ou substituir tal dispositivo.

A Lei 5.692/71, promulgada no contexto dos governos militares, reorganizou a educação de nível básico no país, extinguindo as escolas normais e passando a formação que antes essas escolas realizavam para uma habilitação de segundo grau chamada de Magistério, enfatizando a formação profissional rápida dos trabalhadores e a privatização do ensino. Essa mudança fez com que a formação perdesse especificidades, generalizando de forma que sendo uma habilitação deveria ajustar-se em grande parte ao currículo geral do segundo grau (atual Ensino Médio). Era um currículo disperso, reduzido de formação específica em razão dessa nova estrutura curricular.

Os profissionais da educação lutavam contra esse modelo, pois entendiam que necessitavam de uma formação com caráter mais específico, desenvolvendo nos educandos consciência capaz de transformar as condições escolares e por consequência, da sociedade como um todo. Esse modelo era criticado emergencial, fragmentado, de caráter, em suma, conservador, distante do que a sociedade necessitava. 
No campo da formação para as séries iniciais, a partir de 1982, são implantados os Centros Específicos de Formação e Aperfeiçoamento do Magistério (Cefam), criados com intuito de melhorar a qualidade da formação de docentes dos anos iniciais, visto os problemas encontrados com a formação de professores na Habilitação de Magistério. Os Cefams ofereciam formação em tempo integral, com três anos de curso, currículo voltado á formação geral e à pedagógica, enfatizando as práticas de ensino. Esses centros foram se expandindo e conseguiram qualidade na formação que ofereciam. No entanto, foram fechados nos anos seguidos ao decreto da Lei de Diretrizes e Bases da Educação Nacional no 9.394/96.

De acordo com Pontes:

Com a Reforma Universitária (Lei 5.540/1968), foi previsto que a formação de professores para o ensino secundário (disciplinas gerais ou técnicas) seria desenvolvida em cursos de nível superior indicados pelo Conselho Federal de Educação (CFE). Tal exigência foi relativizada pelo Decreto-Lei no 464/1968, que instituiu o exame de suficiência a ser realizado em instituições oficiais indicadas pelo referido Conselho, visando à habilitação dos profissionais para o ensino técnico, enquanto não houvesse número suficiente de professores.

A formação de docentes para educação profissional passava por muitas dificuldades e ausência de medidas efetivas. Com a criação, em 1978, dos Centros Federais de Educação Tecnológica pela Lei ${ }^{\circ} 6.545,30$ de junho de 1978, estes são incumbidos:

Art. $2^{\circ}$ - Os Centros Federais de Educação Tecnológica de que trata o artigo
anterior têm os seguintes objetivos:
I- ministrar ensino em grau superior; a. de graduação e pós-graduação, visando
à formação de profissionais em engenharia industrial e tecnólogos; b. de
licenciatura plena e curta, com vistas à formação de professores especializados
para as disciplinas especializadas no ensino de $2^{\circ}$ grau e dos
cursos de formação de tecnólogos; II- promover cursos de extensão,
aperfeiçoamento e especialização,
objetivando a atualização profissional na área técnica industrial; III- realizar
cursos na área técnica industrial, estimulando atividades criadoras e
estendendo seus benefícios à comunidade mediante cursos e serviços
(BRASIL, 1994, p.33).

Assim, desde 1978, os CEFETs possuem a prerrogativa de formar professores para disciplinas específicas das áreas técnicas, contribuindo para enfrentar a carência de professores formados em faculdades de educação que estivessem habilitados para essas disciplinas, tradicionalmente ocupadas por técnicos e bacharéis. A formação desses professores se deu a princípio através de "medidas consideradas emergenciais", cursos de capacitação docente apropriadamente denominados "Esquemas I e II".

Em 1997, após a aprovação da Lei de Diretrizes e Bases n. 9394/96, o Decreto Federal no 2.208/1997 estabelece que as disciplinas técnicas poderiam ser lecionadas por professores, instrutores e monitores, em função de sua experiência profissional. Para tanto, eles deveriam ser formados previamente ou em serviço, através de cursos regulares de licenciatura ou de programas especiais de formação pedagógica (PONTES). Os programas especiais foram regulamentados posteriormente em legislação específica. 
$\mathrm{Na}$ atualidade, desde a LDB (especialmente após as alterações trazidas pela lei 12.796/20131, três modalidades de Educação Profissional são admitidas no que tange à formação de professores: a) Formação em Nível Médio (Curso Normal); b) Formação em Nível Pós Médio (Institutos Superiores de Educação); c) Formação em Nivel Superior mediante licenciaturas (a Pedagogia é também uma licenciatura) e por complementação pedagógica aos bacharelados.

Esta indefinição atual (estamos em 2020) quanto ao tema lança duvidas e incertezas quanto aos rumos que a Formação de Professores pode vir a tomar no futuro, em especial quando consideramos as políticas públicas tratadas em momentos anteriores no Brasil, as quais não trazem para este Campo Profissional diretrizes claras e um projeto de formação que permita contemplar as necessidades da sociedade brasileira e nem tampouco as dificuldades experimentadas pelos recém-formados ao fim de seu trajeto formativo. 


\section{REFERÊNCIAS}

BRASIL. Instituto Nacional de Estudos e Pesquisas Educacionais Anísio Teixeira. Educação profissional técnica de nível médio no censo escolar. Brasília: Instituto Nacional de Estudos e Pesquisas Educacionais Anísio Teixeira, 2006.

BRASIL. Lei $\mathrm{n}^{\circ} 9394$ de 20 de dezembro de 1996. Decreto $\mathrm{n}^{\circ} 2.208$ de 17 de abril de 1997.

CASTIONI, Remi. A trajetória das políticas de educação profissional voltadas ao mercado de trabalho na última década. In: NOZAKI, Izumi (Org.). Educação e trabalho: trabalhar, aprender, saber. Campinas-SP: Mercado de Letras; Cuiabá-MT: UFMT. Seminário Educação.2008.

CIAVATTA, Maria. Formação integrada a escola e o trabalho como lugares de memória e de identidade. Trabalho Necessário. Ano 3, 2005. p. 1-20. Disponível em ww.uff.br/trabalhonecessario/TN03\%20CIAVATTA,\%20M.pdf.

CUNHA, L. A. O Ensino de Ofícios Artesanais e Manufatureiros no Brasil

Escravocrata.São Paulo: Ed. Unesp; Brasília: Flacso. (2000a).

CUNHA, Luiz Antônio. O ensino profissional na irradiação do industrialismo. 2. ed. São Paulo: Editora UNESP; Brasília, DF: FLACSO, 2005.

FONSECA, Celso Suckow da. História do ensino industrial no Brasil. Rio de Janeiro. Escola Técnica Nacional, 1961. 2 v.

FRIGOTTO, Gaudêncio.Educação e crise do capitalismo real. São Paulo: Cortez, 1995.

GARCIA, Nilson Marcos Dias, LIMA FILHO, Domingos Leite. Politecnia oueducação tecnológica: desafios ao Ensino Médio e à educação profissional. GT-9 - Trabalho e Educação, para apresentação na 27 . Reunião Anual da ANPEd, Caxambu, 2004).

KUENZER, Acacia Zeneida. Educação Profissional: Categorias para uma Nova Pedagogia do Trabalho. Boletim Técnico do SENAC, vol. 25, n. 2, maio-agosto 1999. Disponível em http://www.senac.br/informativo/BTS/252/boltec252b.htm acessado em outubro de 2011. , Acácia. Ensino médio e profissional. São Paulo: Cortez, 1997.

MANFREDI, Silvia Maria. Educação profissional no Brasil. São Paulo: Cortez, 2002.

MINISTÉRIO DA EDUCAÇÃO.Programa de Expansão da Educação Profissional. Disponível em http://www.mec.gov.br/semtec/proep, acessado em outubro de 2011.

SAVIANI, Dermeval. Sobre a concepção de politecnia. Rio de Janeiro: FioCruz, Politécnico da Saúde Joaquim Venâncio, 1989. 
SILVEIRA, Zuleide Simas. Contradições entre capital e trabalho: concepções de educação tecnológica na reforma do ensino médio e técnico. Jundiaí: Paco Editorial, 2010.

ZIBAS, Dagmar L. Ser ou não ser: o debate sobre o ensino médio. Cadernos de Pesquisa. São Paulo, Cortez/Fundação Carlos Chagas, n. 80, p. 56-61, 1992 a.

Recebido em: 15/01/2022

Aprovado em: 05/02/2022

Publicado em: 10/02/2022 